\title{
Problems and Countermeasures in the Course of Visual Communication Specialty in the "Internet +" Era
}

\author{
$\mathrm{Hu} \mathrm{Bo}{ }^{1, \mathrm{a}}$ \\ ${ }^{1}$ School of Art and Design, Hubei Engineering University
}

a kavana1011@126.com

\begin{abstract}
Keywords: Internet+; Visual communication; Professional courses; Problems and countermeasures
\end{abstract}

\begin{abstract}
Under the current era background, the rapid development of Internet technology has provided a new development path for the development of the visual communication profession in the country under the background of the information age. It requires continuous updating of the curriculum and changes in traditional teaching methods and methods. Break the traditional content limitations, create scientific and reasonable teaching content, improve the original teaching system, and improve teaching efficiency and level. This article mainly studies the problems and countermeasures of the visual communication professional courses in the Internet+ era.

In recent years, with the advent of the era of economic globalization, the speed of cultural dissemination has been accelerating, and the cultural and creative industries have also exhibited an infinite prosperity. In the process of the development of society, the demand for visual communication design talents is also increasing. However, the traditional teaching content and curriculum model can no longer meet the social requirements for talents. According to the survey of the job market, professional design companies, departments, and first-line design departments do not have a single requirement for talents, but they are multifaceted. It is not enough to have design skills alone. What is lacking in the society is a large number of comprehensive talents. Such talents not only need professional theoretical knowledge, but also have rich practical experience. Continuous innovation in development can bring about improvement in capabilities and bring about development of the enterprise. Greater benefits.
\end{abstract}

\section{Problems in the Curriculum Design of Visual Design in the "Internet +" Era}

There is a big gap between the professional courses of visual design in the Internet+ era and actual social development. In the context of the information age, visual communication design has undergone substantial changes. Due to the continuous development of new media technologies, the market's needs are constantly changing. In the current curriculum setting, many times when the trend and trend of the development of the times cannot be followed, the curriculum setting does not match the development. There is still a lot of breakthrough content in the curriculum system. There are many loopholes in the curriculum structure. At present, many of China's colleges and universities in the field of visual communication and design are still relatively traditional. They are simply a combination of theory and practice. The basic knowledge of theoretical knowledge includes basic software teaching such as sketching, graphic design, and plane composition, as well as professional courses such as advertising, poster design, and web page design. There is a lack of content related to new media in the setting of the course, and the content of the course does not match the era of the Internet. With the advent of digital media, the art design is also constantly developing. The traditional 2D design has been transformed into a multi-dimensional design. The new products have been widely used in smart electronic devices such as mobile phones and computers, but the related curriculum settings However, it did not keep up with the pace of development of the times. The curriculum was very rigorous, there was no clear curriculum goal, and there was no close connection between the courses. Due to the irrational curriculum design, students cannot follow the requirements of the curriculum, resulting in inefficient learning. And after the theoretical course, no corresponding practical courses are arranged. The two cannot be 
effectively combined and affect the overall teaching effect.

Teaching mode problem. At present, the process of visual design in colleges and universities in our country is based on teacher lectures. Students learn passively, and teachers occupy a dominant position in the classroom. In recent years, with the continuous development of our country's economy, the requirements of companies for talent have also been continuously improved. The existing teaching model cannot adapt to the requirements of the development of the times. The actual situation of students and the needs of society are far from each other. Teaching efficiency cannot be effectively improved, and students' future employment will have a bad influence.

Textbooks out of style. Visual communication design is an applied curriculum. The content of the curriculum and the content of the teaching should follow the changes in the industry. However, judging from the current situation, the content of textbooks cannot meet the actual needs of social development. The textbooks used by many colleges and universities in the teaching process were written many years ago, and they were not updated in a timely manner. In the current social context, the gaps in years are enormous. The students have learned many years before, and the skills they learn are also very backward.

Less opportunity to applied experiments. In the process of visual communication design teaching, theory and practice are equally important. However, in practical teaching, there are few opportunities to provide students with practice. Student's practice is usually the contact experiment in the operation, and there is no real practice. In such a situation, students cannot effectively grasp their own learning, and teachers do not understand the actual learning of students.

Teacher's knowledge out of date. As society develops, technology advances. While various industries are developing, they need to update their knowledge in a timely manner. However, in the actual development process, teachers are affected by the traditional teaching model, and personal professional knowledge and skills are not updated in a timely manner. In the process of visual communication design, teachers simply follow the script and follow the traditional teaching materials. Due to the untimely updating of their own knowledge, the overall development of students was affected.

\section{Meet the requirements of the times and improve the construction of the curriculum system}

Build a curriculum system according to the job requirements of the Internet+ era. In the process of curriculum setting, we must keep up with the needs of the development of the times, aim at the needs of competent positions, cultivate the ability of students to work, and clarify the standards for employing people. In the arrangement of the courses, order-based training should be carried out to enhance the students' abilities in the teaching and improve the related system construction.

Establish a complete curriculum system to optimize the curriculum structure. Grasp the scientific rationality of the course, increase the program visual communication design professional, conduct market research on related positions of the company, understand the needs and distribution status of each job position, make a clear analysis of the responsibilities of each job, so that the course setting is more targeted Sex. According to the requirements of each post, the arrangement of the course structure and the cultivation of students' abilities are carried out. The whole process is to conduct market research first, then establish the goal of talent cultivation, and finally build a corresponding curriculum system. In terms of ideology, it is necessary to correctly handle the relationship between courses, including the relationship between basic courses and professional courses, theoretical courses and practical courses, and re-construct the course teaching system.

The curriculum serving for the application of undergraduate. The new curriculum should be set up in keeping with the requirements of the development of the times, and scientific methods must be adopted to adjust the content of the curriculum in a timely manner. Since entering the information age, new media technologies have developed rapidly. The state has determined the development strategy of informatization to drive industrialization, and has continuously joined the digital and networked forms in the process of personnel training. Under the new education concept, the pattern of visual design personnel training needs continuous improvement. While ensuring 
theoretical knowledge, it will increase the number of technical practice courses so that students can effectively integrate and improve students' knowledge in the process of learning a variety of subjects. The ability to practice innovation, cultivate students' innovative thinking, and promote the students' all-round development. Curriculum education should be guided by the actual needs of the market, continuous advancement in science and technology development, and continuous extension of art design, but it is obviously lagging behind in the design of courses, especially in the field of digital art design. Therefore, we must always pay attention to Internet technology. The development of the curriculum constantly adjusts the content.

Curriculum settings should meet the requirements of the development of the times. Under the special era background of the Internet age, we must conduct a study of visual communication techniques in a more scientific and systematic way. We must constantly improve related curriculum settings and change traditional education methods and teaching models. In the process of cultivating talents, it is necessary to proceed from actual job requirements, arrange related courses in accordance with the needs of social development, provide targeted education for students, and adjust teaching content according to the students' actual learning conditions., make the courses independent and interconnected.

Under the development of the era, visual design teaching also faces many difficulties. The traditional curriculum can no longer meet the requirements of the development of the times. In order to comply with the requirements of social development, it is necessary to change the curriculum. From the current situation, the fusion of visual design and media will take a long time. In this process, colleges and universities should always make preparations to keep up with the pace of development of the times and cultivate the high-quality talents needed by society.

Pay attention to lecturer's professional knowledge training. In the process of teaching, teachers also need to constantly update their knowledge. We must constantly improve ourselves and improve our skills. Schools should arrange teachers for training and strengthen exchanges between teachers and students. For newly recruited teachers, regular training is also required to constantly update the knowledge.

Pay attention to students' practical ability. Visual communication design is an application-oriented curriculum that places a higher requirement on students' practical ability. Therefore, schools can adopt a school-enterprise joint approach to provide students with more practical opportunities. In the course of practice, discover your own deficiencies and then conduct targeted learning.

Strengthen communication among researchers, staff, and employees. The development of a discipline can not be separated from the communication between all levels of personnel. The same is true for visual communication design courses. During the course of the course, it is necessary to increase exchanges between researchers, faculty, and practitioners. Through teaching experiments, researchers find out the correct theoretical knowledge and adapt to the development needs of the society.

Build a school-enterprise cooperation framework to complement each other. In the process of professional teaching, the school can choose the right enterprise for school-enterprise cooperation according to the actual teaching situation, enhance the practical ability of teachers and students in the process of school-enterprise cooperation, and achieve win-win results. First of all, most teachers are lacking practical experience in the teaching process. Can choose the professional talents of the company to teach the teachers in the school to enhance the teachers' comprehensive skills. Secondly, students in the school can improve their practical ability by practicing within the company and enhance their own competitiveness and level in the future development process. A practice base can be established in the school for students to practice. For enterprises, in this process, they can cultivate excellent talents that are suitable for their own companies and contribute to the future development of the company. 


\section{Conclusion}

This article studies the curriculum of visual communication design from a variety of aspects and proposes that in the future development process, it is necessary to continuously reform the curriculum, adjust the teaching content and teaching structure, and provide students with a more scientific curriculum system. The visual communication design curriculum is an applied curriculum. In the process of teaching, practical teaching is also very important. Practical teaching also plays an important role in teaching. Through the study of the ideas in this paper, we aim to improve the efficiency of teaching, improve the overall quality of teaching, and continuously cultivate high-quality talents suitable for the needs of social development so that students can be more competitive in future employment.

\section{References}

[1] Li Xiuqi. The reshaping and expansion of documentaries in the "Internet + " era[J]. Movie Literature, 2018, (1):23-25.

[2] Liu Cun, Wang Zengcheng, Li Mei. Exploring the curriculum setting of visual communication specialty in engineering colleges from the angle of creative industry: Taking Hebei University of Technology as an example[J]. Art Science and Technology, 2016, (1): 88.

[3] Liao Qiaoxin. Research on the Necessity of Curriculum Design for Visual Communication Specialty in Normal Colleges and Universities of Henan Province [J]. Literary Life-Wen Hai Yi Yuan, 2013, (12):242-242. 